\title{
Social relations and challenges to consuming less in a mass consumption society
}

\begin{abstract}
Increasing numbers of people in welfare societies express worries about their ecological footprint. Some make efforts to significantly reduce their consumption. Because people have been socialized into a society of mass/excess consumption, there are great challenges. How can someone learn to downsize when society incessantly compels her to continue with mass consumption habits? This article demonstrates, theoretically and empirically, how social relations, within a societal context of mass consumption, shape the conditions for transforming lifestyles to reduce consumption. It contributes to sociology as well as a growing interdisciplinary literature on reduced consumption by focusing specifically on challenges related to social relations. The study uses a qualitative approach and an interview study of 24 people in Sweden making significant efforts to reduce their consumption. Findings - both perceived challenges and creative ways of coping with them - are related to four analytical themes: (1) the intersection of everyday rituals and consumption; (2) the norms and normality of mass consumption; (3) social comparison and status consumption; and (4) social and community support for reducing consumption.
\end{abstract}

Keywords: Sustainable consumption, lifestyle, downsizing, reduced consumption, transformation

THERE IS GROWING public anxiety and discontent about escalating climate and ecological crises. An increasing number of people in welfare societies worry about their ecological footprint, and some are making an effort to reduce their consumption significantly. Groups of such people are known under a variety of labels: downsizers (Schor 1998), anti-consumers (Lee, Ortega-Egea \& García de Frutos 2020), voluntary simplifiers (Osikominu \& Bocken 2020), and minimalists (Uggla 2019), and they try out practices such as buy-nothing periods and similar (Isenhour 2010; Callmer 2019). ${ }^{1}$ A growing interdisciplinary field of research explores the various external (institutional, structural, socio-material, and cultural) and internal (pertaining to mindsets,

1 Examples of other terms for describing the phenomenon include downshifting (Nelson, Rademacher \& Peak 2007); brand resistance/rejection (Boström 2019), slow consumption (Sassatelli \& Davolio 2010), and lifestyle political consumerism (Stolle \& Micheletti 2013). 
knowledge, skills) barriers and opportunities these people face. ${ }^{2}$ One dilemma they encounter is particularly intriguing: How can a person learn to downsize when mass consumption society in various ways compels her to incessantly continue with mass consumption habits? People in welfare societies are embedded in institutional, cultural, and social contexts that pressure them to reproduce mass consumption habits (Boström 2020). Mass consumption is here considered as the totality of consumption of commoditized goods and services, the span of which is increasing in a process called "commoditization" (Sassatelli 2007). This study will not consider all possible macro or micro factors, but focuses instead on conditions, opportunities and challenges related to social relations, a topic to which sociology is particularly well suited to contribute, theoretically and empirically. Even if social relations appear as a topic in the literature (see findings reported in the following theoretical framework section), it is striking, as Rebouças and Soares (2020:11) found in their recent systematic literature review on voluntary simplicity, that "the majority of studies focuses on the individual as a unit of analysis" (see also Kennedy \& Hauslik 2018 for similar arguments). The argument developed in this paper is that various social-relational aspirations and pressures make it particularly challenging for people to deviate from a mass-consuming way of life, which also means that consideration of social relations is key to understanding the conditions for resisting and reducing consumption.

The aim is accordingly to demonstrate theoretically and empirically how social relations, within a societal context of mass consumption, shape the conditions for transforming lifestyles in the direction of reduced consumption. The article can thereby contribute to both sociological theorizing and the interdisciplinary literature on environmentally motivated reduction of consumption (and lifestyle transformations) by focusing specifically on how social relations impact on the opportunities and challenges people face. This is an interesting area for sociological theorizing; the sociology of consumption has generally developed with reference to pro-growth, mass consumption society and culture, but the perspectives developed from this and related sociological fields can be utilized for understanding a countermovement. This area, not least when focusing on social relations, also demonstrates sociology's potential to contribute to a wider interdisciplinary field of studies on (un)sustainable consumption and lifestyle transformation.

Empirically, the article is based on a qualitative interview study which explored the practical, personal and social-relational challenges (obstacles and benefits) people face when trying to change their lifestyle by significantly reducing consumption. These are people who intentionally try to downsize their consumption out of concern for the environment. The interviews were done before the Covid-19 pandemic. A methodological limitation in terms of external validity is that this group of people may not experience all, or the same kinds of social-relational pressures as more mainstream

2 See, for instance, recent literature reviews on voluntary simplicity (Osikominu \& Bocken 2020; Rebouças \& Soares 2020) and anti-consumption (García de Frutos, Ortega Egea \& Martínez del Río 2018). 
consumers do; for example they may be less prone to engage in status consumption. Conclusions therefore need to be cautious. On the other hand, if even this group of people experiences social-relational pressures, it is likely that such pressures are very common. Focusing on such groups may also provide indications of social-relational benefits of reducing consumption and of how people can deal with the challenges.

The next section develops the theoretical framework with four analytical themes and integrates key findings from previous literature. After that, the qualitative interview study and methodological arguments are presented. The results section is divided into five parts. The first of these describes the interviewed people's process of downsizing. Then research findings are presented according to the four analytical themes connected to everyday rituals, norms and normality, social comparison, and social support. Finally, the conclusions are presented.

\section{Theoretical framework: social relations and reduced consumption}

The theoretical perspective developed here is based on some key work in the sociology of consumption and on sociological and socio-psychological theories about how agency and meaning are shaped by social relations (both intimate and more distant) in one's social life. I emphasize an intersubjective agency dimension (Berger \& Luckmann 1966; Blumer 1986[1969]; Collins 2004) in reproducing or challenging patterns of mass/excess consumption (Boström 2020). This perspective stresses how people are born into and naturalize their social lives in their material contexts by developing worldviews, norms, roles, habits, and identities - a process which is profoundly shaped by modern consumer culture (Schor 2005; Bauman 2007; Sassatelli 2007; Dittmar 2008). Macro-institutions (economic, political, cultural) deeply shape everyday social life, but cannot alone explain reproduction of mass consumption (Boström 2020). Social agency must be included to understand the reproduction of social structures and culture, as well as to understand conditions for change.

Consumer desires are not just personal; they are social as well (Belk, Ger \& Askegaard 2003). As emphasized in social practice theory, the thinking, feeling, and acting of individuals are embedded in social relations in the socio-material environment as well as informed by cultural values (Shove 2010; Spaargaren 2011; Kennedy $\&$ Hauslik 2018). The material culture perspective adds important insights (Miller 1998, 2010). The material landscape, including all physical objects, provides meaning and symbolic significance to social relations and identities. Daniel Miller (2010) emphasizes dialectics, arguing that things produced and consumed by people are seen as objectifications of (joint) aspirations, values, thoughts, fantasies, and so on, while these objectified things shape people in return by providing conditions for ways of thinking, feeling, acting, and desiring in the world. These broad perspectives emphasize the social embeddedness of consumption, and hence bring about an understanding that downsizing of consumption must also be an inherently social affair. On this basis, I develop additional analytical tools - four themes - to focus in particular on the role of social relations. First, we establish and confirm social relations by means of activities 
(everyday rituals) and devices, in which consumption is a key component. Second, the ways in which we take care of these relations are guided by norms as well as ideas about normality related to consumption. Third, we make comparisons within and across social relations, with consumption as a means and yardstick, and such comparisons and social judgments in turn relate to structures of social stratification. Fourth, we support each other in social relations and networks, and such support is critical for people's ability to transform lifestyles.

The first theme regards how the establishment and confirmation of social relations intersect with consumption. A fruitful theoretical point of departure is the theory of interaction ritual chains formulated by Randall Collins (2004). Collins stressed the importance of everyday rituals for developing and confirming social relations and group solidarity. For group members (a family or another social group), everyday rituals create a mutual focus of attention and shared mood, which in turn lead to social bonds, norms, valued symbols, and positive emotional energies. Therefore, interaction rituals are the glue of social life. Such rituals are in many ways tied to consumer objects (meat, cars, gifts), activities (shopping, dinners, holidays, birthday parties, concerts) and settings (the shopping mall, the café); and this intersection is seen in expressions of love, romance, and care (Miller 1998; Collins 2004; Boström 2020, 2021) as well as in the commoditization of intimate and family life (Schoonmaker 2006; Sassatelli 2007; Hochschild 2011; Lorenzen 2017). Previous studies of voluntarily reduced consumption reveal how challenges to reducing consumption relate to the importance of consumption - in the form of consumer symbols, a mutual focus of attention, or requisites for rituals - when friends, family members and relatives are socializing together (Cherrier, Szuba, Özçağlar-Toulouse 2012; Grauerholz \& Bubriski-McKenzie 2012; Joyner Armstrong, Hiller Connell, Lang et al. 2016; Callmer 2019). Likewise, previous studies of birthday parties (Schoonmaker 2006) and gift giving (Lorenzen 2017) reveal the dominance of consumer culture in such everyday rituals. Presents and rituals such as Christmas and Halloween parties play a significant role in socializing children into consumerist culture and expectations (Schor 2005). At the same time, people can be creative and invent interaction rituals with a less consumerist focus (Schoonmaker 2006; Lorenzen 2017). A reduced focus on consumption can also free up more time and attention for meaningful relationships with family, friends, and community (Osikominu \& Bocken 2020).

The intersection between consumption and close social relations relates to wider norms and conceptions of normality in society, which is the second analytical theme. An individual socialized into a particular generation of mass consumption will perceive contemporary modes and levels of consumption as normal (Schor 1998, 2005; Shove 2003, 2010), and mass consumerist norms will impact on social relations. Cherrier, Szuba and Özçağlar-Toulouse (2012:401) use the metaphor of a "glass floor" to represent sociocultural standards that prevent people from achieving the goal of reducing their carbon footprint. The glass floor is seen as the minimal level of socially required consumption. "Under this threshold, an individual transgresses the socially dominant rules of the consumer society and faces risk of social exclusion and marginalisation". 
They discuss symbolic representations, social norms and the social construction of needs, which create obstacles for people trying to reduce their consumption. The glass floor represents the stock of items that are almost impossible to lack without clashing with dominant social norms in society. Such norms and standards of normality are taken for granted, and are not recognized because of firm socialization. Because normalization is a gradual and unconscious historical process, it prevents groups of consumers from imagining alternatives, such as seeking a happy family life with less consumption and a lower standard of living (Jackson 2005; Miller 2010; Jenkins, Nixon \& Molesworth 2011). Also, many consumer habits are taken for granted because people unconsciously imitate each other (Zorell 2020).

Deviation from living standards and social norms is associated with shame, stigma, and risk of social exclusion. The fear of being stigmatized as deviant and acting outside the mainstream has been documented in previous studies on (un)sustainable consumption practices (Bauman 2007; Black \& Cherrier 2010:445; Isenhour 2010; Shove 2010; Cherrier, Szuba \& Özçağlar-Toulouse 2012; Joyner Armstrong, Hiller Connell, Lang et al. 2016). While owning a hybrid car is celebrated, not owning a car can be experienced as socially awkward (Cherrier, Szuba, Özçağlar-Toulouse 2012).

Norms and normalization shape expectations. These expectations may be practical, such as how long a product is expected to last before falling apart, but they can also include how technology and material objects are embedded within social relations. For instance, a smart phone can result in new norms and expectations regarding social life, such as expectations that people should be reachable at all times (Hobson 2019). There are also expectations regarding appearance. Maintaining oneself as employable may require not only having the right $\mathrm{CV}$ and expertise, but also engaging in significant amounts of consumption, and having the taste and knowledge to consume the right kinds of products (Bauman 2007).

Norms and standards of normality can be revealed by alternative-lifestyle experiments, such as reducing consumption for a period, or just by remembering role models from the past, for instance a grandmother who lived well with scanty resources. Research shows that experimenting with buy-nothing periods can be revealing to the individual and show how deeply consumption permeates everyday social life, particularly within social relations (Grauerholz \& Bubriski-McKenzie 2012; Joyner Armstrong, Hiller Connell, Lang et al. 2016; Callmer 2019).

The third analytical theme is social comparison, which connects with social stratification and indirect structures of social relations. Social life is stratified into social classes and status groups, and sociology has a rich tradition of theoretical and empirical knowledge about how such social stratification fuels consumption. Using concepts such as "conspicuous consumption" (Veblen 1992[1899]), "distinction", "taste", "habitus", "cultural capital” (Bourdieu 1984[1979]; Schor 1998; Wilk 2002), and "identity" (Dittmar 2008), sociology and social psychology have long theorized about how consumption, including mechanisms of both affiliation and distinction, intersects with such stratification. In addition to complying with social norms and ideas around normality, as emphasized above, people express social identity, status, and 
distinction by consuming the right things and, not least, the right amount (Schor 1998, 2005; Dittmar 2008; Jackson 2017; Boström 2020). Having limited opportunities for consumption because of relative poverty can have serious social and health consequences (Wilkinson \& Pickett 2018), but such negative consequences can also be felt by relatively well-off people who voluntarily downsize. People trying out a buy-nothing period have experienced recurring difficulty with refraining from comparing themselves with others (Isenhour 2010; Callmer 2019:94-96). Even if such an experiment is done consciously for a limited period, feelings of envy and anxiety about appearances and missed opportunities may arise (Joyner Armstrong, Hiller Connell, Lang et al. 2016). Such worries can extend to other members of the social group, such as parents worrying about peer pressure affecting their children.

Walther and Sandlin's interviews with voluntary simplifiers who had children found several obstacles caused by the families' interaction with a broader social network involving relatives, friends, schools, co-workers, and neighbors. These voluntary simplifiers "must cross personal moral boundaries that they would not have to cross if they were not parents" and they "have to demonstrate their care and love for a child by consuming or showing proof of consumption" (Walther \& Sandlin 2013:43).

Social comparison and status may also provide an opportunity, particularly if norms in society (theme 2) change in the direction of becoming more pro-environment. In such contexts, conspicuous green consumption can be an important social motivator and element of social positioning, even though this effect is more pronounced for alternative consumption (e.g. purchasing a Tesla automobile) than reduced consumption (Portwood-Stacer 2012; Carfagna, Dubois, Fitzmaurice et al. 2014).

The final analytical theme is social support in relations and networks. Such support includes receiving moral and emotional support for one's lifestyle transformation project from close relations (family, friends, relatives, colleagues), those who are of greatest significance to the individual in which the norms, habits, competencies, and settings of social life (home, workplace, digital platform) are shared. Osikominu and Bocken (2020) found in an interview study of voluntary simplifiers, that the most frequently mentioned "enablers" were interviewees' partners or new peers who think in similar ways. Walther and Sandlin (2013) stress the importance of the family as a unit for transmitting, through socialization, the values and habitus of frugality to coming generations, as well as for understanding conflicts and negotiations between frugality values and mainstream consumer culture. The very act of practicing downsizing and voluntary simplicity with others can foster new values such as otherness-orientation, benevolence, and a sense of collective responsibility (Osikominu \& Bocken 2020; Rebouças \& Soares 2020). Moreover, the importance of social capital has been emphasized in previous studies of reduced consumption (Schor 1998; Schor \& Thompson 2014; Hagbert \& Bradley 2017). Social capital requires not just the family context, but also the wider social network in the community, to gain symbolic resources (signaling that one is not alone in the lifestyle changing project), cognitive resources (knowledge, ideas, skills, alternative role-models), and material/infrastructural resources (e.g. sharing platforms) needed for lifestyle change. Engaging in civil society action together 
with others can also be a way to deal with anxiety and transform dissonant emotions into creative action and feelings of hope (Ojala 2016).

To sum up, by employing various theoretical resources from general sociology, and the sociology of consumption specifically, this theoretical framework deals with how drivers of consumption - including both positive and negative emotions - relate to socializing aspirations and the strengthening of social bonds within concrete social relations (family, friends, etc.). These concrete social relations are, moreover, always related to wider norms and conceptions of normality in society, for instance about how social relations ought to be cultivated by consumption, as well as, both directly and indirectly, to stratified social relations in society, which can be manifested in social comparison, judgment, and peer pressure, for example. Hence, various kinds of social and community support are necessary to resist the forces of mass consumption and provide alternative reference groups and models. It should be stressed that the themes are analytical, which means that a concrete practice such as a birthday party could relate to all four themes. It is a ritual that the group engages in together to bolster group belonging (theme 1), it relates to norms and ideas about how a "normal" birthday party should be performed (theme 2), and it relates to worries about children's peer pressure (theme 3) and to social support (theme 4) for seeking out less consumerist ways to practice gift-giving and host parties.

\section{Method and material}

The research documented in this paper is based on a qualitative approach and consists of an interview study with people who are reducing their consumption out of concern for the environment. The study involves adults with experiences of growing up and living in a mass consumption society (Sweden). 22 interviews were conducted with 24 individuals. The study applied a relatively open form of interviewing, using a few standardized questions and several follow-up questions linked to the specific narratives of the interviewees. The interviews lasted between 40 and 80 minutes, and took place between November 2018 and January 2020, thus before the outbreak of the Covid-19 pandemic.

The ambition was to achieve a heterogeneous sample with regard to gender, residence, and age, and the participants were 18 women and six men between 24 and 78 years old, living in both rural and urban areas and in different types of housing. The sample had a somewhat academic and middle-class bias (as seen in similar studies; see Carfagna, Dubois, Fitzmaurice, et al. 2014), although factors such as occupation, employment status, educational level and income levels varied. Interviewees were recruited by an advertisement circulated in different social networks. From a relatively rich influx of expressions of interest, a selection was made to achieve heterogeneity by considering information about potential interviewees' experiences and efforts, which they briefly wrote about in an initial e-mail. 17 interviews were done face to face (by the author) and five by Skype (by a research assistant). In interview excerpts below, the interviewees are designated by codes. For example, the code "IP8f34" means "Interview Participant 8, Female, 34 years of age". 
A relatively short interview guide with a set of open questions was employed. The interviewees could talk freely about their ambitions and experiences, as well as practical, personal, and social challenges. Interviewees were asked to talk about their reasons for reducing their consumption, their goals, what they have done, which consumption areas they focus on, what obstacles and facilitating factors they have encountered, if and in what ways they have tried to overcome difficulties, and what new insights they might have gained. Questions were also asked about what the lifestyle transformation means for them, as well as aspects of their lives that have become better or worse due to their reduced consumption. Because this interview study was not intended to collect personal sensitive data, there were no questions about the participants' political opinions and ideologies, religious beliefs, or health conditions.

In addition to the interviews, five interviewees were asked to complement the interview by writing monthly memory notes for one year. Each month they could fill out a questionnaire containing open-ended questions. They could freely reflect upon difficulties, opportunities, new insights, and positive/negative experiences. A short follow-up interview was held afterwards with four of them.

Even if the sample reflects niche experiences in society, it is important to consider such experiences on a wider scale as well. The participants are more environmentally committed than the average citizen, and thus are not representative of the current broader societal context. However, they can be seen as representing important experiences regarding lifestyle and societal transformation. If we assume that the present planetary environmental challenges will continue and become more acute, it is not far-fetched to believe that reduced consumption will be a necessity for a much larger part of the population in the future. In terms of representativeness, it is however also important to underscore that for the people interviewed for this study, the process has been undertaken voluntarily and deliberately.

\section{Reducing consumption: a long-term and stepwise process}

Based on the interview material, this first section describes some common features in the downsizing process undertaken by the people studied. Subsequent sections are structured according to the four themes and focus more explicitly on social-relational challenges and support in the lifestyle transformation process.

The material suggests that reducing consumption in a mass consumption society is typically a slow, long-term and stepwise process (see also Osikominu \& Bocken 2020). The interviewees generally portrayed themselves as having been environmentally conscious for a long time, sometimes for decades. The ambition to significantly reduce their consumption typically started recently, however, such as a couple of years back. Among their reasons, interviewees mentioned increased understanding of the climate issue, their ecological footprint, and the planetary crisis in general, and some also cited more personal reasons (e.g., consumer fatigue, reflections on what really matters in life).

Reduction of one's consumption can comprise a variety of practices such as less commoditized consumption of material objects and services, alternative consump- 
tion, repairing, reusing, and redesigning things, second-hand consumption, and more non-commoditized experiences (Shaw \& Moraes 2009; Callmer 2019; Osikominu \& Bocken 2020). The interviewees employ a variety of strategies. Reduced consumption could take the form of buying fewer things, but could also be tied to using things less often (e.g. the car) or in a less resource-demanding way (e.g. reduced indoor temperature). Interviewees spoke of either refraining from or reducing consumption of commoditized objects and services (aviation, cars, meat, clothing, electronics, kitchenware, energy, fashion, etc.). They also search for and develop alternatives such as home-grown vegetables, repairing things, buying second hand, sharing things within social networks, using libraries (books, equipment), driving alternative cars (electric, biogas, hybrid), installing solar panels, using public transport or cycling, avoiding flying to vacation destinations, buying organic/vegetarian/vegan food, reducing food waste, and giving alternative presents. They carefully consider what they buy and why.

Several interviewees also mentioned more holistic strategies such as reducing working hours and accepting reduced income, or moving to a place of residence that facilitates their lifestyle transformation (Osikominu \& Bocken 2020; Rebouças \& Soares 2020). There is much variation in how different interviewees employ the abovementioned strategies and in their levels of engagement (Rebouças \& Soares 2020). Some have come far in their lifestyle transformation; others are experimenting in an earlier phase. Yet very few of them considered themselves to have reach an end point. A dependence on mass consumption, both structural and cultural, is felt by all, even if it can be counteracted.

Several of the interviewees described reducing their consumption as a stepwise process. It is about successively adding new areas of attention, forms of effort, routines or decision-making rules. They gradually learn more and acquire new skills needed for the new lifestyle. One activity leads to another, which is known as a spill-over effect (Osikominu \& Bocken 2020). The interviewer asked about consumer items that are especially difficult to cut down on or give up altogether. Interviewees mostly mentioned meat, dairy products, cars, or car use. Products and services connected to their children were frequently portrayed as a difficult area (see also Isenhour 2010; Walther \& Sandlin 2013). Difficulties were often related to the family situation or other social groups, and not primarily to individual needs and desires, thus indicating social-relational challenges. The interviews showed that the process of reducing consumption is fundamentally social. Even if interview questions were addressed to an individual person, the relation to a partner, family or another social context appeared central. The following sections discuss this in detail in relation to the four themes.

\section{Fostering social relations with everyday rituals of (anti-)consumption}

Social relations, intimate relations within families, and relations with friends and associates can be a source of consumption because participants in such relations validate each other and create social solidarity through the joy, pleasure and shared attention 
that group consumption can offer. Consuming things together, or enjoying prepackaged commoditized experiences as a group, can be a source of positive emotional energy that the members of a social group wish to experience over and over, and that strengthens their bonding.

Living an everyday social life without engaging in commoditized interaction rituals seems difficult or even impossible in the current mass consumption society. Yet, such rituals can be channeled in alternative directions: having a glass of wine at a café rather than shopping with a friend, enjoying a vegetarian dish instead of meat, vacationing by train in Europe instead of flying to a more distant destination, working together in the garden and enjoying its fruits together. Interviewees spoke in various ways about the benefits and challenges of a less consumerist focus with regard to social relations and socializing with others.

Sometimes old habits of consumption are accepted because of a felt need to maintain family rituals. A common theme in the interviews was difficulties related to the family situation rather than to individual needs and desires. I illustrate this topic with a narrative from a woman living in a rural setting who has developed a holistic, anticonsumerist approach. She discusses the car question.

\begin{abstract}
We're not ready to give up the car completely. Because, actually we could manage our everyday life quite well, but it wouldn't be possible for us to do what we value on the weekends. And that is, to get us out into nature. To different nature reserves and so on and like hang around there. That would be much harder. We probably would not do it to the same extent if we had taken public transportation. And similarly, it would be more difficult to visit our parents and siblings who live, well, 200-250 kilometers away. Because it would be hard to bring along everything you need to have, and it will be difficult to get out to the summer cottage where they live half the year. (IP21f38)
\end{abstract}

For this woman, the car is not a consumer symbol to be celebrated - such as in rituals connected with masculinity norms - but is perceived as a technological necessity to preserve social relations and maintain the ritual of weekend excursions. Similar findings about everyday dilemmas were also documented in research on people who are trying to minimize their carbon footprints (Cherrier, Szuba \& Özçağlar-Toulouse 2012). Flying, or taking the car, may represent a desire to be mobile, to be able to reach distant places. Flying to a distant place can be a symbol of escape. Being able to fly or take the car can be seen as a way to guarantee one's ability to remain socially connected.

One kind of everyday ritual that several interviewees described as a challenge is gift-giving. Participants expressed that they found it difficult to resist the consumerist frame when it comes to gifts (Schoonmaker 2006; Lorenzen 2017). This emerged as a surprisingly important topic in my interviews, given that the interview guide did not include any explicit questions about this practice. Presents may not be the largest expenditures for a person or family, yet they are symbolically charged and appear to symbolize and legitimize consumer culture, and help socialize children into 
consumption-related expectations (Schor 2005). A majority of the interviewees spoke about this theme, mostly in terms of a social obstacle. This is an issue that causes everything from mild discussions to serious disagreements and conflicts, albeit temporary ones. Signaling that one wants to abandon the ritual of exchanging Christmas presents with relatives and associates can be interpreted as provocative. Interviewees expressed feeling uneasy about this issue and spoke of dilemmas and compromises. Presents for children can be seen as symbols of mass consumption, a culture that parents may want to protect their children from, perhaps by fostering alternative symbols. However, not giving presents to children is also seen as impossible. One woman said you cannot send your child to a buddy's birthday party with a package of organic raisins.

The following interviewee is representative of those who see this domain as full of conflicts. She says that she has refrained from exchanging Christmas presents at work, which led to heated discussions:

\begin{abstract}
You become a bit of a killjoy when you express such opinions. So there's a dilemma sometimes, that you feel strongly that others may be doing wrong or that you're contributing to something that you yourself think is wrong, at the same time as you don't want to be that boring person who ruins other people's enjoyment. At the same time as maybe one should ruin other people's enjoyment to make them think about their behavior. So it is a very difficult balancing act, still wanting to have a good relationship with people around you. (IP8f34)
\end{abstract}

Discussions and conflicts are experienced as tiresome and interfering with the harmony of the social group. A few interviewees mention positive consequences of starting such discussions, even though they are troublesome initially. There are also several examples of what types of gift-giving practices that the interviewees are inventing. They talk about reducing the amount and frequency of giving presents, only exchanging secondhand items with relatives, or only giving experiences or homemade things and avoiding anything commoditized, including prepackaged experiences. Such creativity has also been documented in previous studies of birthday parties (Schoonmaker 2006) and gift giving (Lorenzen 2017) among environmentally conscious people.

For an individual, a divorce or the death of a spouse can reveal something about (mass)consumption and everyday rituals within a small social unit. One retired widow says that she consumes almost nothing nowadays and that she has become very "anti-consumption" since the death of her husband, despite the fact that he too was environmentally conscious. At least five of the interviewees who are single have previously lived with a partner (divorcees, widows). All of them express that the ending of the relationship led to less consumption. The opposite, getting married, can result in painful compromises. Two of the interviewees found life partners with roots in other continents. This involves difficult decisions regarding whether or not to visit relatives, as it would require flying.

A further important driver of consumption, apart from family relations, has to do with forming social bonds among friends. I illustrate this topic with a narrative from a 
woman who reflects on past times when her interest in the outdoors, which she shared with her friends, involved much unnecessary consumption of sports equipment.

It's difficult when you're in a group like that. It's easy to buy what others have, because you think it's necessary to display your identity with a certain jacket. (IP14f50)

For different reasons, her participation in this group of friends ended, which was a wake-up call and an opportunity to question the consumption within this social circle:

Then I was no longer in a milieu of people obsessed with equipment. When I started going out into nature on my own, I realized more what you need and don't really need. Sometimes I felt ridiculously over-dressed when I was just going out for a walk in the woods. Then I stood there like a question mark and wondered why do I have this stuff? Things got worn out and when I went to buy new ones, it was completely absurd how expensive it was, and they started talking about technology; there's such an extreme level of technical detail in the tiniest fiber of the sports equipment. (IP14f50)

The fancy equipment was needed as a requisite for participating in the group's outdoorlife rituals, not for survival in nature. What this woman expresses - and there were several similar stories in the material - is that because of the social forces of the group and its interaction ritual chains, it can be difficult even to see one's high level of dependence on mass consumption habits until one gets some distance from the group and encounters alternative kinds of knowledge and reference groups. Counteracting the dependence thus needs to be a deliberate act and requires a favorable context and social relations.

In sum, findings show that downsizers creatively invent many new and less commoditized, though still emotionally energizing, rituals that succeed in strengthening social bonds (Collins 2004). Fully escaping from mass consumption culture seems impossible, however, because it would involve the risk of rejecting one's most important relationships. Consumption remains important, even for downsizers, as a means of expressing love and care (Miller 1998), as can be seen in such activities as the vacation trip (reliance on car, aviation), festive meals, and gift-giving practices. Although participants learn from the stepwise downsizing process itself, it is also interesting to observe that changes in relationships, such as a divorce or making new friends, help them recognize everyday consumerist rituals.

\section{Challenging the norms and normality of mass consumption}

This second theme is about how the intersection between consumption and close social relations relates to wider norms and conceptions of normality in society. It links with the first theme because interaction rituals, such as gift-giving, tend to give rise 
to norms (standards of morality, in Collins's (2004) terminology) in that such rituals should be respected and fulfilled in particular ways. The pressure that consumerist norms and reflections exert on what is considered normal was a frequent topic in the interviews. Interviewees spoke frequently about "aha" experiences and how their previous perception of the "normality" of (excessive) consumption was exposed by the lifestyle experiment of consuming less. They spoke of positive experiences such as increased reflective capacity, better control of spending habits, and a sense of having enough things (see also Grauerholz \& Bubriski-McKenzie 2012; Joyner Armstrong, Hiller Connell, Lang et al. 2016; Callmer 2019). There were challenges as well, which reflect such notions as the "glass floor" discussed earlier. The analysis of the material found three types of challenges. First, many interviewees feel they often come across as a killjoy when they challenge consumption norms (which connects with the first analytical theme because as a killjoy you threaten socially agreed interaction rituals). They use terms such as the "the nail in the eye", "odd", "uncomfortable", "killjoy", "party pooper", "bore", "the master", "know-it-all", and so on [additional Swedish words: Bror Duktig, miljömupp, Svarte Petter, fröken-PK, besserwisser] to express how they feel in various situations with relatives and workmates. Interviewees say that this feeling of being labeled does not affect their own consumption very much, but that they are affected in the sense that they are selective about when they discuss their views openly and dare to be the difficult person in the break room. One man says he does not even have to say anything; he still gets comments: "They always feel compelled to apologize when I'm around" (IP23m42). This common experience of feeling like a killjoy reflects a hegemonic consumer norm. Openly rejecting this norm creates tension in social relationships.

A second theme regards conflicts, criticism and bullying in one's social milieu. A few interviewees had experienced conflicts in their closest relationships (Cherrier, Szuba \& Özçağlar-Toulouse 2012), even if this is not a frequent topic in the interview material. One woman describes how her views and ambitions deviate from those of her husband and children, which leads to discussions and arguments. A couple of divorced interviewees' narratives show that some problems remain because they have children together with their ex-spouses. The children get the things they want from the other parent.

One man talks about his experience of being bullied and humiliated in his social environment, and that he can be regarded as an outcaste (Svarte Petter) and several other caricatures, and that he has lost friends (see also Osikominu \& Bocken 2020):

I'm a bit surprised and worried that when you talk about things you do that are good for the climate and the environment, and are committed, you're considered an idiot. I've been called, by both friends and by relatives, in both public and more private settings, both an environmental muppet and an environmental Taliban, eh yeah idiot, yeah, who doesn't understand anything, and so on. In fact, it also means that I no longer hang out with some friends. (IP5m54) 
Difficult discussions, negotiations and conflicts can also occur in the workplace. The following interviewee, who experiences much humiliation and repression, has had the most negative social-relational experiences of anyone in the interview material, but several others also mention losing friends and acquaintances. A woman who sometimes perceives herself to be a party pooper talks about how both colleagues and neighbors can be provoked by her. Her residential area:

is characterized by fairly high incomes, people who live in a very unsustainable way. [They] build a lot a new buildings ... and build and build. There have to be more and more charming, and nicer and nicer houses. Traveling everywhere, all the time. Two cars in all households... (IP12f36)

The third theme concerns clashes between social norms: old, dominant, and new. All interviewees, without exception, perceive that the dominant norms are tied to mass consumption. As indicated above, this dominance of pro-consumerist norms makes it challenging to deal with social relations within families, and particularly among relatives, friends, neighbors, and colleagues. Some interviewees are more bothered than others about feeling they are viewed as the deviant one. Isenhour (2010:466) describes "Sweden's conformist culture" as a barrier to confronting consumption norms: "this egalitarian ethos and focus on solidarity within Sweden means that many Swedes are hesitant to separate themselves from the comfort of mainstream consumerism and to abandon the safety of Swedish cultural symbols and normative frameworks".

At the same time, both old and new norms come to the rescue. Old norms are related to thrift and self-sufficiency, and new or reinvented norms have much to do with recent changes in the public debate and media coverage about climate change and other environmental issues. Interviewees perceive that lifestyle practices related to vegetarianism, veganism, second-hand shopping, frugality, the sharing economy, and similar have become more recognized and socially accepted, even respected. Cutting down on one's consumption out of concern for the environment is no longer socially deviant to the same extent as before. One man mentions media coverage: "All the media coverage of the climate threat makes it very easy for me to explain to people why I don't want to travel" (IP23m42). The fact that one is in a buy-nothing period can be regarded as a positive norm that fits with current trends.

So it feels like it isn't: "are you so poor that you're not allowed to buy anything for yourself?" Instead it's more like: "Well done, that you can manage it." (IP10f50)

In sum, the downsizers expressed, in various ways, something akin to a glass floor (Cherrier, Szuba \& Özçağlar-Toulouse 2012). Several think they are killjoys, and several have experienced conflicts and demanding discussions with people as well as a hegemonic pro-consumerist norm. The fact that high levels of consumption are generally considered normal in society constitutes a hindrance to having everyday discussions. At the same time there are positive signs that norms are changing. What seems to be crucial is the 
possibility to find and surround oneself with people and reference groups that confirm one's identity and aspirations (see theme four, below). This may be easier said than done, however, because one generally does not choose one's relatives, neighbors, and colleagues.

\section{Resisting status consumption and social comparison: more difficult for parents}

As the previous section showed, the groups interviewed for this study experience the dominant social norms, and do not want to be killjoys or to appear socially odd. Nonetheless, they do not generally appear worried about losing their identities or social status if they fail to consume the "right" things in the "right" amounts. Rather, for them pride was linked to consuming less than others, and having a smaller carbon footprint than the average citizen. In this contrasting sense, social comparison and distinction was not unimportant, and can be associated with some cultural capital and eco-habitus (Portwood-Stacer 2012; Carfagna, Dubois, Fitzmaurice et al. 2014).

Nonetheless, the interviewees did feel some pressure related to comparisons regarding (status) consumption. Again, gift-giving emerges as an issue. Giving (and being able to give) presents signals something about who you are and want to be. A woman (IP10f50) says that apart from food and medicine, presents are the only type of thing she cannot avoid buying, despite a general shopping pause. She says that she does not want to appear worse or poorer than people in her surroundings. She has a limited personal economy, but much of what she saves is spent on "nice presents". Another topic is mentioned by a woman who quit her job to invest in her own crafts business. She reasons that this choice can be seen as resigning from the prestige of having a career: "viewed with traditional eyes, it's like a step down somehow" (IP22f50). She believes that this competition for career and status is a big hindrance for many people trying to reduce their consumption, but she was able to do it, and she mentions that positive responses from her social network have been very important.

The big obstacle, however, concerns interviewees with children. While parents may not be very worried about how they position themselves in relation to status consumer objects, they do worry about their children. There is pressure among parents, because of social comparison and judgment, to maintain status consumption for their children (toys, fashion, electronic devices, gifts, long-distance vacations), and this makes it difficult to reduce consumption. They do not want their children to be bullied, to seem poor or odd, or to feel envious. One father reasons as follows:

Much of my consumption is about my children, and I haven't really figured anything out that works. Of course, I try to hold back, but I buy significantly more, or we buy significantly more than I would like. And it's also very much a question of comparisons, with other children getting more. On this issue, I don't have... I don't know the key to going forward with that thought. It's rather that I don't want my children to feel neglected or set aside or treated worse by other people's children. It's like a very sore spot. (IP23m42) 
It can be difficult to convince one's children about the problematic nature of fashion, brands, electronics, shopping, and vacations in far-away places, especially in the face of peer pressure, advertisements, children parties, and so on. A mother with two children (IP12f36) says:

IP: It's really clear with the older child [7 years] that it's starting to increase. She has very specific wishes about things.

Interviewer: In first grade?

IP: Yes.

Interviewer: So there may be some signals from friends?

IP: Very much. We also live in a residential area with very high socio-economic status, high average income among the parents, and this is noticeable among the children as well. They have gadgets, so infernally many gadgets. That creates some kind of pressure.

Peer pressure is mentioned by several participants:

The children can come home and ask "Why don't I have this thing that my friends have?" or "Why do we do that?" The question often arises: "Why do we only have one car when everyone else has two cars?" So these are the things you encounter. (IP8f34)

It's the highest dream to be like everyone else when you're that age, to have everything you think everyone else has. (IP11f40)

She [9-year-old daughter] wants new things and she wants to travel outside Sweden... it has to be Thailand, where her friends have been to. And yet she goes to school with extremely environmentally friendly people. (IP17f47)

It is apparent that children make things difficult, when it comes to reducing or refraining from consumption (see also Schor 2005; Isenhour 2010; Walther \& Sandlin 2013; Callmer 2019). What interviewees say they can do is to try to make their children more aware and teach them impulse control and how to see through the advertisements and brand labels. Interviewees also spoke of avoiding places and situations where there are lots of advertisements, such as by having ad-free TV. They may be able to teach their children such critical reflexivity, but it is more difficult to urge them to ignore the social comparison game in school and between friends. One interviewee mentioned taking a more drastic approach; their family chose to live in a somewhat secluded rural area to reduce opportunities for social comparisons. But her children have not yet entered their teens.

In sum, the interviewees remind us with their narratives that they are not just individuals. Caring for others within one's relationships includes caring about how others are affected by social positioning and status comparison via consumption. When it 
comes to bolstering their own identity as individuals, status consumption and material possessions appear almost to be a non-issue. They do make comparisons, but express feeling pride in complying with a counter-consumerist norm. The dilemma for them is that their choices affect others around them, especially their children. Thus, social stratification, and mechanisms related to social comparison and judgment, do shape the conditions and opportunities for people to transform their lifestyles by reducing consumption, even if this mechanism mainly operates indirectly though caring for others.

\section{Social and community support for downsizing}

An implication of the results presented in previous sections is that successful downsizing cannot just be an individual undertaking. Support within one's social relations is essential. Consumption rituals for social bonding, norms and normality related to mass consumption, and issues of status consumption and social comparison are topics that need to be examined and confronted together, within various social spheres and communities. It is evident from the interviews that couples plan their everyday lives together. They support, discuss, debate, negotiate, compromise, question purchases, help resist each other's impulsive buying, assess purchases made, and critique and try out activities together. One partner may be more committed than the other, although many interviewees describe how essential support and compliance from the less committed partner is. The couple's children - whether small, teenagers, or young adults - are also often included in the family discussions. The social sphere beyond the household (some interviewees were single households) includes relatives, friends, work colleagues, and civil society associations. Being able to change one's lifestyle requires joint discussions about alternative activities, social norms, and how to cope with peer pressures and reference groups connected to high levels of consumption. Group members need to discuss creative ways to cope with such pressures. Within the family and among neighbors and colleagues there is also a need to come to agreement about a variety of matters because you share an economy and a home with family, an office or shared workspace with colleagues, and local facilities with neighbors.

Social validation is important to not feeling odd, for example if one does not wear fashionable clothes. Several interviewees describe their circle of friends in this way. A woman active in a transition group says she can feel like an oddball [Swedish: kuf] sometimes but,

there [in the transition group] you're all made of the same stuff [Swedish: samma skrot och korn] ... It's nice to be able to say that you save things and such, and not be seen as weird. (IP6f45)

Several mention that one's circle of friends is important to not feeling deviant, particularly in cases when one's colleagues, relatives and other acquaintances tend to adopt dominant mass consumption norms. It should also be emphasized that having a less 
consumerist focus in general - and the free time that comes from working less - can be perceived as beneficial for fostering social relations, something several interviewees implicitly or explicitly touch on. People can be creative in developing everyday socialbonding rituals with less focus on consumption items and consumerist settings.

Interacting with like-minded peers can also be an important enabler because it makes you more committed:

When you make such decisions together with others then you become a bit more motivated, perhaps to ... to implement what you've thought about, because you've promised to do it in front of each other. (IP19f31)

Social support also encompasses a wider circle than just one's most intimate relations and closest friends. Several interviewees were involved in various groups, such as study circles or transition networks. These provide social capital, which is important to gaining symbolic resources (legitimacy), cognitive resources (ideas, tips), and material/ infrastructural resources. Several interviewees also expressed that they felt a sense of connection through groups in social media. They mentioned how likes and positive comments were encouraging. Indeed, several interviewees described the importance of being surrounded by a network of like-minded people, both physically and on social media. This support is an important source of tips, information, and knowledge about alternative ways of living, but also helps one to be more self-confident, to confirm the value of one's own choices in life, and to gain some hope (Ojala 2016).

I have become more and more involved in an association of people who are "climate activists" or something like that. It's easier when there are more of us who share the same worries about the future and our extreme overconsumption! (IP12f36, memory notes February)

Several interviewees spoke of feeling a need to do more than only taking individual responsibility and to engage in more outward-oriented action to complement one's efforts. Interviewees spoke about their actions in relation both to concrete others (as potential role models, by discussion, provocation) and to a larger collective. The types of action vary, and include participating in civil society associations such as transition networks, arranging study circles, running websites, writing blogs, confronting consumerist norms and practices in the workplace, and discussing on social media or in other contexts. Social support in a social setting can provide the self-confidence needed to be more assertive in relation to others who disagree (see theme two above).

Looking beyond the downsizers' immediate social network, one finds the sociomaterial arrangements in the local community and region. Interviewees discussed many practical challenges to living a life that is less reliant on consumption. This involved issues of time, mobility, and proximity to needed resources, the workplace and friends and relatives. Some of the interviewees lived in a city, others in a rural area, so the possibilities and challenges related to time, infrastructure, and distance differed a 
great deal. What was possible for one (e.g., access to safe bicycle lanes) was a problem for someone else. Time, distance, and logistics are no small matters for the downsizers, especially if they live a (social) life without a car. Everyone needs to juggle their time and achieve some work-life balance. Regardless of place of residence, local physical infrastructure has not generally been constructed for a downsized life, particularly not a car-free life, although several interviewees could see improvements related to new means of transportation, better cycling infrastructure and more second-hand, repair, and borrowing outlets (tools, equipment, books). It is outside the scope of this paper to go more deeply into issues of physical infrastructure. However, it is important to stress that such temporal, geographical, and infrastructural aspects, including issues of mobility and proximity, also connect very closely to social life dynamics and possibilities to maintain social relations. It is of key concern that people with aspirations to reduce their consumption have ready access to a social network. Not everything happens on the internet and social media, not even during a pandemic. People need to be able to physically meet with members of their social network.

In sum, support from one's social relations (family, friends, relatives, colleagues), which has practical, cognitive, moral, and emotional aspects, appears necessary for transformative lifestyle change. People share social lives and physical circumstances, and they need alternative role models, positive reference groups, enriching discussions and negotiations, and motivation and encouragement from peers and family members. They rely on a facilitating infrastructure in the community. All such support is essential for their ability to cope with challenges related to the other three themes: less commoditized rituals, confronting social norms and conceptions of normality, and resisting social comparison and judgment.

\section{Conclusion}

There are several institutional, infrastructural, practical, and personal challenges to reducing consumption. This article, however, has emphasized the equally compelling challenges related to social relations. Some of these challenges (theme 1) are linked to the ways in which consumption intersects with various interaction rituals that people frequently engage in to confirm social relations and strengthen social bonds. Even if downsizers can creatively invent many new less commoditized rituals, and gain time for a renewed focus on social relations, fully escaping from mass consumption culture seems impossible, as it would imply losing the ability to express love, care, and friendship. Other challenges (theme 2) relate to dominant consumerist norms and standards of normality, which cause difficulties for downsizers, as they may feel like killjoys and experience conflicts and difficult discussions with acquaintances. However, positive signs of changing norms in society give downsizers some leverage and possibilities to find and surround themselves with positive role models and reference groups. Still other challenges (theme 3) are related to social stratification and comparison, in that even for a committed downsizer it is sometimes socially important to consume the right things and the right amounts. However, this pressure was especially strongly felt 
by parents worrying about their children's consumption. Thus, social stratification and mechanisms related to social comparison and judgment shape conditions and opportunities for reducing consumption, even if this mechanism operates indirectly. In each of these three thematic areas - everyday rituals, norms and normality, social comparison - the people interviewed for this study were able to creatively invent new practices and could speak about gaining insights. A crucial factor for positive development was receiving support (theme four) from one's social relations and wider social network (family, friends, relatives, colleagues), which includes practical, cognitive, moral, and emotional aspects. Such support appears necessary for transformative lifestyle change.

My conclusion is that, in addition to institutional and infrastructural factors, these four themes related to social relations are critical for understanding limits and possibilities for transforming one's lifestyle away from patterns of mass/excess consumption. Therefore, in future studies and policy about sustainable lifestyle transformation which is an extremely important topic considering the current climate and ecological crises - increased attention must be given to social-relational challenges. The framework of the four themes offered here contributes by providing theoretical resources to study these challenges and, more generally, the social embeddedness of (over)consumption and resistance to it, and thus to avoid an overly individualistic conception of consumer behavior and lifestyle change. Again, it should be stressed that the four themes are analytical. In concrete practices - birthday parties, commuting to work, vacationing, dining - consideration ought to be given to all these aspects of social relations and how they intersect. Moreover, one must be attentive to both positive experiences (pride, positive emotional energies related to joint activities, etc.) and negative experiences (anxieties related to social judgment, fear of being a killjoy, appearing deviant, etc.) involved in both continued overconsumption and downsizing practices.

As regards appreciation of the efforts made, one final observation worth stressing is that interviewees generally reported that many aspects of their personal and social lives had become better as a result of consuming less (and in some cases, working less), and that these improvements significantly outweighed the disadvantages. None of the interviewees wish to return to a situation of more consumption. Rather, they spoke of an increased quality of life. This is perhaps not very surprising, given that they embarked upon this process of lifestyle change voluntarily, and similar results have been documented in previous studies of downsizers (Jackson 2005; Dittmar 2008; Kasser 2009, 2017). At the same time, such experiences are noteworthy, not least because many interviewees were surprised by this effect. An interesting direction for further studies would be to compare experiences among this category of voluntary downsizers with cases of involuntary reduction of consumption, for example that caused by the Covid-19 pandemic (see also Boström 2021). What are the possible insights gained from comparing voluntary and involuntary disruption of consumer practices?

As addressed in the introduction, an obvious methodological limitation in terms of external validity is that these groups of people may not experience all or the same kinds of social relational pressures as more mainstream consumers do. For instance, mainstream consumers may feel even more dependent on consumerist norms and 
standards of normality, as well as on status consumption, and they may spend time together with acquaintances in more consumerist ways - fostering their social bonds. They may relate to groups of people and be embedded in social relations in which it is more challenging to deviate from the rituals, norms and habits of a mass-consuming way of life. If such challenges are perceived as strong and inhibiting among very committed frontrunners of lifestyle change, they are likely to be even more compelling to more mainstream environmentally conscious consumers. This is an interesting topic for future research. Sociology can contribute studies on many aspects of social dynamics related to transformative lifestyle change, and can thus play an important role in this wider interdisciplinary field of research.

\section{References}

Bauman, Z. (2007) Consuming life. Cambridge: Polity Press.

Belk, R.W., G. Ger \& S. Askegaard (2003) "The fire of desire: A multisited inquiry into consumer passion", Journal of Consumer Research 30 (3):326-351. https://doi. org/10.1086/378613

Berger, P. \& T. Luckmann (1966) The social construction of reality: A treatise in the sociology of knowledge. London: Penguin books.

Black, I. \& H. Cherrier (2010) "Anti-consumption as part of living a sustainable lifestyle: Daily practices, contextual motivations and subjective values", Journal of Consumer Behaviour 9 (6):437-453. https://doi.org/10.1002/cb.337

Blumer, H. (1986[1969]) Symbolic interactionism: Perspective and method. Berkeley: University of California Press.

Boström, M. (2019) "Rejecting and embracing brands in political consumerism", 205-225 in M. Boström, M. Micheletti \& P. Oosterveer (Eds.) The Oxford handbook of political consumerism. New York: Oxford University Press. https://doi. org/10.1093/oxfordhb/9780190629038.013.50

Boström, M. (2020) “The social life of mass and excess consumption”, Environmental Sociology 6 (3):268-278. https://doi.org/10.1080/23251042.2020.1755001

Boström, M. (2021) "Social relations and everyday consumption rituals: Barriers or prerequisites for sustainability transformation?” Frontiers in Sociology 6:723464. https://doi.org/10.3389/fsoc.2021.723464

Bourdieu, P. (1984[1979]) Distinction: A social critique of the judgement of taste. Cambridge: Harvard University Press.

Callmer, Å. (2019) Making sense of sufficiency: Entries, practices and politics. PhD thesis. Stockholm: KTH Royal Institute of Technology.

Carfagna, L.B., E.A. Dubois, C. Fitzmaurice, M.Y. Ouimette, J.B. Schor, M. Willis \& T. Laidley (2014) "An emerging eco-habitus: The reconfiguration of high cultural capital practices among ethical consumers", Journal of Consumer Culture 14 (2):158-178. https://doi.org/10.1177/1469540514526227

Cherrier, H., M. Szuba \& N. Özçağlar-Toulouse (2012) "Barriers to downward carbon emission: Exploring sustainable consumption in the face of the glass floor", 
Journal of Marketing Management 28 (3-4):397-419. https://doi.org/10.1080/026 7257x.2012.658835

Collins, R. (2004) Interaction ritual chains. Princeton: Princeton University Press.

Dittmar, H. (2008) Consumer culture, identity and well-being: The search for the "good life" and the "body perfect". New York: Psychology Press. https://doi. org/10.4324/9780203496305

García de Frutos, N., J.M. Ortega Egea, J. Martínez del Río (2018) “Anti-consumption for environmental sustainability: Conceptualization, review, and multilevel research directions", Journal of Business Ethics 148 (2):411-435. https://doi.org/10.1007/ s10551-016-3023-z

Grauerholz, L. \& A. Bubriski-McKenzie (2012) “Teaching about consumption: The 'not buying it' project", Teaching Sociology 40 (4):332-348. https://doi. org/10.1177/0092055x12441713

Hagbert, P. \& K. Bradley (2017) "Transitions on the home front: A story of sustainable living beyond ecoefficiency”, Energy Research \& Social Science 31:240-248. https:// doi.org/10.1016/j.erss.2017.05.002

Hobson, K. (2019) "'Small stories of closing loops': Social circularity and the everyday circular economy”, Climatic Change 163:99-116. https://doi.org/10.1007/s10584019-02480-z

Hochschild, A. (2011) "Emotional life on the market frontier", Annual Review of Sociology 37:21-33. https://doi.org/10.1146/annurev-soc-081309-150137

Isenhour, C. (2010) "On conflicted Swedish consumers, the effort to stop shopping and neoliberal environmental governance, Journal of Consumer Behaviour 9 (6):454-469. https://doi.org/10.1002/cb.336

Jackson, T. (2005) "Live better by consuming less? Is there a 'double dividend' in sustainable consumption?" Journal of Industrial Ecology 9 (1-2):19-36. https://doi. org/10.1162/1088198054084734

Jackson T. (2017) Prosperity without growth: Foundations for the economy of tomorrow. Second edition. London: Routledge. https://doi.org/10.4324/9781315677453

Jenkins, R., E. Nixon \& M. Molesworth (2011) “'Just normal and homely': The presence, absence and othering of consumer culture in everyday imagining", Journal of Consumer Culture 11 (2):261-281. https://doi.org/10.1177/1469540511402446

Joyner Armstrong, C.M., K.Y. Hiller Connell, C. Lang, M. Ruppert-Stroescu \& M.L.A. LeHew (2016) "Educating for sustainable fashion: Using clothing acquisition abstinence to explore sustainable consumption and life beyond growth", Journal of Consumer Policy 39 (4):417-439. https://doi.org/10.1007/s10603-016-9330-z

Kasser, T. (2009) "Psychological need satisfaction, personal well-being, and ecological sustainability”, Ecopsychology 1 (4):175-180. https://doi.org/10.1089/eco.2009.0025

Kasser, T. (2017) "Living both well and sustainably: A review of the literature, with some reflections on future research, interventions and policy", Philosophical Transactions of the Royal Society A 375 (2095): 20160369. http://dx.doi.org/10.1098/ rsta.2016.0369

Kennedy, E. \& D. Hauslik. (2018) “The practice of green consumption”, 187-206 in 
M. Boström \& D.J. Davidson (Eds.) Environment and society: Concepts and challenges. Basingstoke: Palgrave. https://doi.org/10.1007/978-3-319-76415-3_9

Lee, M.S.W., J.M. Ortega Egea \& N. García de Frutos (2020) "Anti-consumption beyond boundaries: From niche topic to global phenomena", Psychology and Marketing 37 (2):171-176. https://doi.org/10.1002/mar.21330

Lorenzen, J.A. (2017) "Social network challenges to reducing consumption: The problem of gift giving”, Symbolic Interaction 41 (2):247-266. https://doi.org/10.1002/symb.312 Miller, D. (1998) A theory of shopping. Cambridge: Polity Press.

Miller, D. (2010) Stuff. Cambridge: Polity Press.

Nelson, M.R., M.A. Rademacher \& H.-J. Peak (2007) "Downshifting consumer = upshifting citizen? An examination of a local freecycle community", The ANNALS of the American Academy of Political and Social Science 611 (1):141-156. https://doi. org/10.1177/0002716206298727

Ojala M. (2016) "Facing anxiety in climate change education: From therapeutic practice to hopeful transgressive learning", Canadian Journal of Environmental Education 21:41-56.

Osikominu, J. \& Bocken, N. (2020) "A voluntary simplicity lifestyle: Values, adoption, practices and effects", Sustainability 12 (5):1903. https://doi.org/10.3390/ su12051903

Portwood-Stacer, L. (2012) "Anti-consumption as tactical resistance: Anarchists, subculture, and activist strategy", Journal of Consumer Culture 12 (1):87-105. https:// doi.org/10.1177/1469540512442029

Rebouças R. \& A.M. Soares (2020) "Voluntary simplicity: A literature review and research agenda", International Journal of Consumer Studies 45 (3):303-319. https:// doi.org/10.1111/ijcs.12621

Sassatelli, R. (2007) Consumer culture. History, theory and politics. London: Sage. https://dx.doi.org/10.4135/9781446212684

Sassatelli, R. \& F. Davolio (2010) "Consumption, pleasure and politics: Slow food and the politico-aesthetic problematization of food", Journal of Consumer Culture 10 (2):202-232. https://doi.org/10.1177/1469540510364591

Schoonmaker, S. (2006) "Piece of cake: Children's birthday celebrations and alternatives to consumer culture", Sociological Focus 39 (3):217-234. https://doi.org/10.10 80/00380237.2006.10571286

Schor, J.B. (1998) The overspent American: Why we want what we don't need. New York: Harper.

Schor, J.B. (2005) Born to buy. New York: Scribner.

Schor, J.B. \& C.J. Thompson (Eds.) (2014) Sustainable lifestyles and the quest for plenitude: Case studies of the new economy. New Haven: Yale University Press.

Shaw, D. \& C. Moraes (2009) "Voluntary simplicity: An exploration of market interactions, International Journal of Consumer Studies 33 (2):215-223. https://doi. org/10.1111/j.1470-6431.2009.00760.x

Shove, E. (2003) Comfort, cleanliness and convenience: The social organization of normality. Oxford: Berg. 
Shove, E. (2010) "Beyond the ABC: Climate change policy and theories of social change”, Environment and Planning A 42 (6):1273-1285. https://doi.org/10.1068/ a42282

Spaargaren, G. (2011) “Theories of practices: Agency, technology, and culture: Exploring the relevance of practice theories for the governance of sustainable consumption practices in the new world-order”, Global Environmental Change 21 (3):813-822. https://doi.org/10.1016/j.gloenvcha.2011.03.010

Stolle, D. \& M. Micheletti (2013) Political consumerism: Global responsibility in action. Cambridge: Cambridge University Press. https://doi.org/10.1017/ CBO9780511844553

Uggla, Y. (2019) "Taking back control: Minimalism as a reaction to high speed and overload in contemporary society”, Sociologisk Forskning 56 (3-4):233-252.

Veblen, T. (1992[1899]) The theory of the leisure class. Boca Raton: Routledge. https:// doi.org/10.4324/9781315135373

Walther, C.S. \& J.A. Sandlin (2013) "Green capital and social reproduction within families practising voluntary simplicity in the US”, International Journal of Consumer Studies 37 (1):36-45. https://doi.org/10.1111/j.1470-6431.2011.01050.x

Wilk, R. (2002) "Consumption, human needs, and global environmental change”, Global Environmental Change 12 (1):5-13. https://doi.org/10.1016/s09593780(01)00028-0

Wilkinson, R. \& K. Pickett (2018) The inner level: How more equal societies reduce stress, restore sanity and improve everyone's well-being. London: Penguin books. https://doi. org/10.1002/ajhb.23334

Zorell, C.V. (2020) "Nudges, norms, or just contagion? A theory on influences on the practice of (non-)sustainable behavior", Sustainability 12 (24):10418. https://doi. org/10.3390/su122410418

\section{Author}

Magnus Boström is a professor of sociology whose research covers environmental sociology, sociology of consumption, political sociology, and organization studies. His research interests include politics, representation, consumption, action, and transformative learning in relation to various transnational environmental and sustainability issues.

\section{Corresponding author}

Magnus Boström

School of Humanities, Education, and Social Sciences, Örebro University

70182 Örebro

magnus.bostrom@oru.se 